\title{
The Release of Nelson Mandela: Effect on the Johannesburg Securities Exchange
}

\author{
Costas M. Stephanou \\ University of South Africa, S.A \\ Gawie S. du Toit \\ University of South Africa, S.A \\ Marius J. Maritz \\ University of South Africa, S.A
}

\begin{abstract}
What determined the value of South African assets after the unbanning of the African National Congress (ANC) and the release of Nelson Mandela? Economic or political events? This paper employs a dynamic version of the APT model for the period from 1991 to 1998 to determine whether the increase in volatility on the JSE changed the specification of the APT model as it applied to the Financial \& Industrial Index of the Johannesburg Securities Exchange (JSE). The finding is that political events in late 1991, and economic events in mid 1994, changed APTM's specification. This would indicate that during periods of profound political change, political events drive stock market prices (JEL G310).
\end{abstract}

Keywords: arbitrage pricing theory model, Johannesburg Securities Exchange, political events, economic events.

\section{Introduction}

In the early nineties the focus of interest in South Africa was very much on political changes in the country. The unbanning of the African National Congress (ANC) and the release of Nelson Mandela in 1990 represented an important milestone in the history of South Africa. Political events following the unbanning of the ANC and the release of Nelson Mandela culminated in the election of a Government of National Unity and the end of white minority rule in the country.

Economic growth performance in South Africa was rather depressed

* We thank the anonymous reviewers for their comments.

(Multinational Finance Journal, 2003, vol. 7, no. 3 \& 4, pp. 153-175)

(C) Multinational Finance Society, a nonprofit corporation. All rights reserved. DOI: $10.17578 / 7-3 / 4-3$ 
in the period 1989 to 1994 . The economy experienced an upswing in the second half of 1993 but economic activity declined in the first half of 1994. Shortly after the establishment of a government of national unity under the presidency of Nelson Mandela, international trade and financial sanctions were dropped and the disinvestment campaign against South Africa was discontinued. As a result economic growth rose to a higher level. The focus of interest in South Africa shifted more and more to the economic performance of the country.

It is a well-known fact that political and/or economic events often have a profound effect on the prices of assets such as equities and bonds. Politics often affects the economy and vice-versa. Current conditions and prospects regarding key variables such as corporate earnings growth or interest rates are often regarded as key market drivers. However, this paper investigates the hypothesis that in the period between the release of Nelson Mandela and the unbanning of the ANC in February 1990 and the first truly democratic elections in South Africa in 1994, political events and not economic events had the greatest effect on the value and volatility of South African assets.

This issue is important, as the confirmation of this hypothesis would mean that the specification of asset pricing models changes in periods of intense political turmoil. More importantly, it is political rather than economic events that will influence asset prices the most.

The identification of any structural changes in asset pricing models and the timing of these changes are economically important. A change in the structure of an asset-pricing model will change the estimates of expected stock returns. This will affect the selection of portfolios, the evaluation of portfolio performance, the measurement of abnormal returns in event studies and the estimation of the cost of capital.

\section{Arbitrage Pricing Theory Model}

The APT model is described by the equation

$$
R_{i, t}=E\left(R_{i, t}\right)+\sum_{k=1}^{K} b_{i, k} f_{k, t}+\varepsilon_{i, t}
$$

where $R_{i, t}$ reflects the actual returns earned by asset $i$ in time period $t$ (where $i=1,2, \ldots, n$ ) and $t=1,2, \ldots, T, E\left(R_{i, t}\right)$ is the expected rate of 
return of asset $i$ for period $t$ at the beginning of period $t, f_{k, t}$ is the $k$ th risk factor that impacts on asset $i$ 's returns (where $k=1,2, \ldots, K$ ). All risk factors have a mathematical expectation of zero, that is $E\left(f_{k, t}\right)=0, b_{i, k}$ is a coefficient that measures the sensitivity of $R_{i, t}$ to movements in the common factor $f_{k, t}$ and $\varepsilon_{i, t}$ is a stochastic error term specific to asset $i$ in period $t$ which measures unexplained residual return (where $E\left(\varepsilon_{i, t}\right)=0$; $\mathrm{E}\left(\varepsilon_{i, t}, \mathcal{\varepsilon}_{j, t}\right)=0$ for all $i \neq j$ and $\mathrm{E}\left(\varepsilon_{i, t} f_{k, t}\right)=0$; see Ross (1976).

This equation is a return-generating process with no underlying theory behind it and is known as the Linear Factor Model (LFM). In order to arrive at the APT model, no-arbitrage conditions would have to be assumed. The central assumption of the APT is that all portfolios that satisfy the conditions of using no wealth and involving no risk must earn no return on average, and this produces what Berry, Burmeister and McElroy (1988) call the "full APT".

$$
R_{i, t}=R_{f, t}+\sum_{k=1}^{K} b_{i, k} \lambda_{k}+\sum_{k=1}^{K} b_{i, k} f_{k, t}+\varepsilon_{i, t}
$$

where $\lambda$ is the risk premium and $R_{f, t}$ is the risk-free rate. If the above equation is compared with equation 1 , it is evident that restrictions have been placed on the intercept term of the linear factor model. Van Rensburg (1996) states that "these restrictions embody, and indeed are a direct algebraic consequence of, the no-arbitrage conditions".

\section{Models for Testing the APT model on a Recursive Basis}

Although the LFM, as was explained previously, is not an asset pricing model, the aim of this model is to identify which risk factors maximize a certain selection criterion (adjusted $\mathrm{R}^{2}$ ) and then to test them in the "full APT model" to see if they are priced. Although they show sensitivity to asset returns, they should in fact be statistically significant. Berry et al. (1988) and Van Rensburg (1996) used a similar approach.

\section{A. Recursive Linear Factor Model}

To establish which risk factors are priced and when they are priced in the LFM applicable on the JSE (financial and industrial sector), the model developed by Pesaran and Timmerman (1995) was used. This is 
a recursive model, which keeps a running score of which risk factors enter or leave the LFM month by month. A base set of nine risk factors was used. At each point in time, the optimal model specification was searched for and a note made of which risk factors were priced.

In each case, the model selection criterion (adjusted $\mathrm{R}^{2}$ ) was applied to linear regression models, using the excess returns on the JSE financial and industrial index as the dependent variable, and subsets of the base set of regressors as the independent variables. As the adjusted $\mathrm{R}^{2}$ statistic assumed a normal distribution of returns, a test for normality of returns was done on the returns of the JSE financial and industrial index to establish its relevance. It was found that the returns were reasonably normal, showing a skewness statistic of .85. The Akaike's selection criterion (Akaike [1973]) which measures the "fit" of a model, was initially chosen along with the adjusted $\mathrm{R}^{2}$ criterion. Since the Akaike's selection criterion tended to choose the same best subset as the adjusted $R^{2}$ criterion, for the sake of consistency, the regression selected was the one exhibiting the highest adjusted $\mathrm{R}^{2}$.

For the set of nine regressors, this meant comparing $2^{9}=512$ models at each point in time, and over the period 20 October 1991 to 21 June 1998 , this yielded a total of $44,544(=512 \times 87)$ regressions to be computed. Weekly data starting from 14 August 1988 were used, the first 156 weeks being taken as the database. The data base was moved along the 87 four week testing period, period by period, adding one period (current period) and dropping one period (oldest period). The choice of the starting date was determined by the availability of weekly data from the data provider (I-Net Bridge).

\section{B. Restricted Nonlinear Multivariate Regression Models}

As noted by McElroy and Burmeister (1988), by regarding the APT as a multivariate nonlinear regression model, with across-equation restrictions, the highly developed least squares statistical machinery for such nonlinear systems can be accessed. The two such "pieces of machinery" used in this articles are the ITNLSUR and the NL3SLS techniques. One of the assumptions made when using ITNLSUR is that the correlation between the factors and idiosyncratic returns is zero. Chamberlain and Rothschild (1983) show that the APT still holds under the much weaker assumption that idiosyncratic returns are correlated across assets, which facilitates the use of the NL3SLS technique. Gallant (1987) provides the mathematical background behind these two 
approaches.

Research published in South Africa in which the APT model was tested was done exclusively using the ITNLSUR technique (Reese [1993] and Van Rensburg [1996]). Clare, Priestly and Thomas (1997) have shown that the choice of the 3NLS over the ITNLSUR technique is critical in determining whether or not the results are valid when testing the APT model on the London Stock Exchange. Since the 3NLS has never been used in South Africa, and there is a possibility that it may be more suitable than the ITNLSUR technique, it was considered essential to use both techniques.

Since testing the APT model involves the joint estimation of factor sensitivities $\left(b_{i, k} \mathrm{~s}\right)$, as well as risk premia $\left(\lambda_{k} \mathrm{~s}\right)$ in nonlinear regressions, there is a possibility that the results may be affected by small sample problems. Garret and Priestley (1997) $)^{1}$ give some guidelines on the number of degrees of freedom per equation necessary to avoid the small sample size problem. The calculated number of 120.08 is adequate according to Garret and Priestley (1997).

\section{Interpretation of Results}

One feature of the best subset LFM is that not all risk factors are included in it. Thus risk factors will not be tested period for period to see if they are priced and a picture of the performance over the period under consideration will not be obvious. Therefore, the only way to evaluate the importance of a risk factor in terms of how often it is priced and when it is priced is to divide the 87 periods into sub-periods and then to compare their performance from sub-period to sub-period. The decision on how many sub-periods to use is restricted by the fact that if the sub-periods are to be tested adequately they must be long enough to make it possible to include each risk factor in sufficient LFMs. The 87 time periods, from 20 October 1991 to 21 June 1998, were subdivided into three equal sub-periods of 29 four-week periods. From the analysis of these three sub-periods, it is possible to establish which risk factors become priced in the APT model over the period under consideration. It was then possible for the researchers to examine any change in the

1. The degrees of freedom for the system of equations are computed using the equation $T D F=N T-(N K+k)-(N+N(N-1) / 2)$, where $N$ is the number of equations, $T$ is the number of observations and $K$ is the number of risk factors. The number of degrees of freedom per equation is $T D F E=T D F / N$. 
specification of the APT model and, depending on the timing of this change, to relate it to any significant political and/or economic event or events. This approach of working backwards in solving the research problem was arrived at after considerable time had been spent on evaluating alternative approaches. For example, the following approach was considered:

(1) Arrive at the specification of the best subset LFMs for the 87 four week periods over the period under consideration.

(2) Test the risk factors in each of the 87 LFMs to see which are priced in the APT model.

(3) If it is assumed - as previous research in South Africa has implied - that a priced risk factor in the LFM will be priced in the APT model, one would be able to predict the specification of the APT model by looking at the betas of the risk factors in the LFM.

(4) It would then be possible to correlate the specification of the APT model directly with a plot of the standardized beta of the risk factors and, subsequently, with political and economic events. The rationale would be that since a political or economic event impacts on a particular risk factor, the risk sensitivity (beta) of this risk factor would change, and provided the impact was significant, the change would be big enough to be priced in the LFM, and subsequently in the APT model.

Unfortunately any approach which involves trying to correlate events with factors is not feasible for the following reason: As will be seen from the results, there is no correlation between a risk factor being priced in the LFM and subsequently being priced in the APT model.

This finding has been recorded before. Van Rensburg (1996) used the same methodology as the authors, namely to test the APT model in the conventional way, which is to find the most significant risk factors in the LFM and then to confirm that they are priced in the APT model. When this did not happen for one particular risk factor, Van Rensburg (1996) stated that "It is, perhaps, surprising to note that Gold price risk is not priced given the importance of this variable to the South African economy". The authors contend that a possible explanation for this anomaly (described by Van Rensburg [1996]) is that as the LFM models the loadings on the unexpected change in the predetermined risk factors it is possible that the unexpected change in a factor is important while 
at the same time the risk premium which represents the importance of that same risk factor is unimportant. Thus the unexpected change in the price of gold may be important while at the same time the price of gold is not. To state this differently, the gold price is unimportant in explaining the mean return of the index over a period of time, but at some point in time the unexpected change in the gold price is important in determining the variation around that mean.

In search of confirmation for this explanation - using the data - the standardized beta of each risk factor plotted against time (the standardized betas are obtained by linear regression using the excess returns on the F \& I index as the dependent variable and the nine risk factors as the independent variables over the 87 time periods) was examined. As the unexpected change in the Dow-Jones index was consistently priced and showed a correlation between being priced in the LFM and the APT model, it was necessary to determine how it differed from the plot of the other risk factors which were not. The plot of the Dow-Jones beta versus time was examined and it showed a significant standardized beta consistently over time. This did not happen with the other risk factors (graphs available on request from the authors). It would therefore appear that before one can expect the risk premium of a risk factor to be priced and hence show a correlation between being priced in the LFM and the APT model it must show a significant standardized beta consistently over time.

\section{Risk Factor, Share and Instrument Selection}

\section{A. Risk Factors Chosen}

Rather than choose only risk factors that could proxy political and economic events in South Africa and then use a set number of these factors (nine) in this study, an alternative approach was considered. In this approach a wide selection of risk factors was made using studies published in South Africa as a guideline and the choice was then narrowed down to the nine most important risk factors. This approach was preferred for the following reasons:

(1) A risk factor such as the Dow Jones index has been shown to be important in all South African studies on the APT model. If a selection process had been used where only factors that can proxy 
political and economic events were chosen, this risk factor would not have been used, and as no other risk factor can explain the variation in returns on the JSE as the Dow Jones risk factor can, the results of the study would have been compromised. By using nine pre-specified risk factors in the APT model ample, allowance was made for risk factors proxying political and economic events to be chosen in the final list of the nine most important risk factors.

(2) As the aim of this study is to identify the effect that political and economic events have on the JSE, risk factors that proxy these political and economic events need to be used in the APT model over 87 test periods in a combination that provides the maximum explanatory power regarding returns on the JSE. If this is not done there will be no benchmark for comparing the behavior of these risk factors over time. In effect what will be measured is the behavior of risk factors proxying political and economic events in an APT model (made up from a selection of the nine most important risk factors), which gives the maximum explanatory power regarding returns on the JSE.

Henn and Smit (1997) and Van der Merwe and Smit (1997) chose Reuter's News Services as their source for news events. They reported that the editorial staff of Reuters classifies news items into the following main categories: corporate affairs, economics, markets and politics. Each main category consists of further subsets. The following are subsets in the economic news category: aid, balance of payments, consumer credit, consumer finances, consumer prices, current prices, current account, economic output, employment, external trade, government borrowing, government finances, housing starts, monetary policy, money supply, performance, personal income, reserves, retail sales, wholesale sales. According to Henn and Smit (1997), "These sub-headings are all macro-economic related". As these subheadings are all macroeconomic related, each of the above 20 subheadings can be tested to establish if they can explain the movement of share prices traded on the JSE.

The task of the researchers in determining which factors could proxy political and economic events was therefore narrowed down to finding a proxy for political news events and proxies for economic news events from the range of choices described in the previous paragraph. This list would then be augmented with any factors found to be important in past 
studies on the JSE.

\section{Risk factor proxying for political events}

In their article Van der Merwe and Smit (1997) tried to quantify the effect of domestic political events on the Johannesburg Stock Exchange by isolating from the news released by Reuters daily, items which were associated with domestic political events. They undertook this study over a five-year period (1990-1995) when South Africa was going through a particularly turbulent time period in its history. They first established that there was a relationship between the number of news events reported during a time frame of one month and the importance of these events. They found that there was a statistically significant correlation between domestic political news events and all-share index volatility, industrial index volatility and volume traded on the JSE. In particular, when they compared the monthly number of political news releases with the volume of shares traded on the Johannesburg Stock Exchange and the all share volatility index, they found that South African domestic political news events explain 59 percent of the volume traded and 15 percent of the all share volatility index.

Henn and Smit (1997) examined the effect of economic events on the JSE during the turbulent five-year period from 1990 to 1995. First they established that there was a relationship between the number of news events reported during a time frame of one month and the importance of these events. In effect the number of economic events were meant to proxy important events such as "the lifting of sanctions and the abolition of the financial rand" (Henn \& Smit [1997]), and to measure their effect on the JSE. These authors found that although the number of South African economic news events has a statistically significant correlation $\left(\mathrm{R}^{2}\right.$ of 0.29$)$ with the volume of shares traded on the JSE there was a weak negative and insignificant correlation in relation to the movement in prices of shares traded on the JSE. Their finding that the number of news items with economic content has very little impact on share market volatility is in contrast to the findings of Van der Merwe and Smit (1997) who found statistically significant coefficients of determination $\left(\mathrm{R}^{2}\right)$ to exist between domestic political news events and all-share index volatility, and volume traded on the JSE. This discrepancy was commented upon as follows: "One explanation for these results could be that economic trends and results are more predictable than political news items and are therefore 
discounted beforehand in the share prices" (Henn \& Smit [1997]).

The volume of shares traded will respond to all types of news events. For the volume of shares traded to act as a proxy of any particular news category, this category must not only be correlated with volume but also with price movements on the JSE. Henn and Smit (1997) have shown that the category of economic news events, although correlated with the volume of shares traded on the JSE, is not correlated with JSE movements. Therefore volume could not proxy for economic events. In contrast, Van der Merwe and Smit (1997) have shown that the category of domestic political news events is correlated both with the volume of shares traded and with price movements on the JSE. Volume could therefore act as a proxy for domestic political news events.

If the period under review in the study undertaken by Van der Merwe and Smit (1997) had coincided with that of this article it would have been possible to use their time series on political news events directly as a factor in this study. Unfortunately the periods did not coincide.

It is possible that either or both of the remaining news categories, namely markets and corporate affairs, could also have influenced volume. Among the nine factors eventually chosen in this study were the Dow Jones Industrial index and dividends paid by companies. The first one is an important sub category of the markets category and the second a very important sub category of corporate affairs. This is according to the definition of news adopted by Reuters. If either of these factors acting as proxies for the two remaining news categories were correlated with the volume of shares traded it would be unlikely that they would be priced in the APT model along with the volume of shares traded. It was later found that both the Dow Jones Industrial Index and dividends paid by companies are priced at the same time as the volume of shares traded. This makes it unlikely that either the markets category or the corporate news affairs category is significantly correlated with the volume of shares.

The elimination of all other news categories would therefore justify the selection of the volume traded on the JSE as a proxy for political news in South Africa.

Risk factors proxying for economic events

According to Herrmanssen (1998), variables such as corporate earnings, monetary conditions, market uncertainty, liquidity and valuations drive 
asset prices. There is a strong correlation between corporate earnings growth and economic growth. The economic recession of the early nineties affected corporate earnings growth negatively. However, the economic recovery that began in 1993 , led to higher corporate earnings. The problem is that information on the real economy only becomes available after some time has elapsed.

The slope of the yield curve - that is the gap between short-term interest rates and the interest rates on investments with longer maturities - is an important signal that is readily available to the investor community. Factors such as inflation expectations and monetary policy often have an effect on the yield curve - or the term structure of interest rates. "Long bond yields are entirely market-determined while short-term interest rates are influenced by monetary policy decisions of the central bank - which, of course, also respect market forces." (Mboweni [1999]). In the early nineties the yield curve in South Africa was signaling that a recovery in economic activity was ahead. However, just after the elections the yield curve was signaling that South Africa was heading for a recession.

Interest rates are an important factor influencing the economy. Interest rates link all three asset classes, namely equities, bonds and cash (Herrmannsen [1998]). Real interest rates - that is the prime overdraft rate minus inflation - increased in the period 1991 to1998. The Bankers' Acceptance (BA) rate is a market-determined rate that reflects conditions in the money market. A declining BA rate indicates easing of money market conditions. The BA rate (short-term interest rate) is important not only because of the implications of the above argument but because, in the words of Herrmannsen, "declining interest rates (year on year change in the BA rate) are nearly always associated with rising equity markets ... the reverse effect does not always hold ... because at the time interest rates are rising, growing corporate earnings often take over as the key driving variable."

Holders of South African assets with values denominated in Rands face a risk whenever the inflation rate increases. In times of rising inflation, investors demand additional compensation in the form of a risk premium built into the yield on their investments. From 1974 to 1992, inflation in South Africa remained in the double digit zone. However, the rate of inflation declined to below 10\% in 1993 and 1994.

The inclusion of the yield curve, the BA rate and some proxy for inflation is therefore essential in the choice of factors proxying economic events. The inclusion of the first two is also essential if 
comparisons are to be made with the Van Rensburg's (1996) study on the APT model before 1990. Oil prices and the Consumer Price Index (CPI) were chosen as proxies for inflation.

It was found that the unexpected component of the yield curve, the BA rate, the oil price and the CPI as well as the business confidence level were correlated with the F\&I Index and could serve as proxies for economic events.

(1) Rate of change in the three-month bankers' acceptance rate

Apart from the reasons given by Herrmannsen (1998) for including this risk factor in this study the following articles confirm its importance. Empirical studies by Correia and Wormald (1987) and Van Rensburg (1995) have shown the BA to proxy inflation expectations and hence consumer prices, which by definition are a subset of economic events. Further, Nel (1994) observed "... the general course and pattern of the BA rate after 1987 was to a greater degree in harmony with that of the Bank Rate than before this time." As the bank rate is controlled by the Reserve Bank the BA rate could be regarded as a proxy for the official monetary policy of the Reserve Bank.

(2) Rate of change of the US dollar crude oil spot price

Because the price of crude oil has been shown by Chen, Roll and Ross (1986) to proxy inflation and by Roberts (1998) to be sensitive to consumer prices, the selection of this risk is justified where it can proxy for consumer prices, which are a subset of economic events as described before.

(3) Rate of change in the consumer price index

This risk factor qualifies as an important category of economic news.

(4) Term structure of interest rates

As the "yield curve is basically the result of monetary policy (Nel [1996])" the term structure of interest rates is an effective proxy for monetary policy, which is a subset of the economic news events.

(5) SACOB business confidence index

Every month, the South African Chamber of Business (SACOB) publishes a figure, which gives an indication of the business confidence 
prevailing in the country. SACOB's business confidence index (BCI) is a composite index, tracking the performance of 13 key economic indicators, which have been judged by business to have the greatest bearing on the mood of businesses. The following indicators currently make up the BCI: the average monthly exchange rate of the rand in terms of the US dollars, the rate of inflation as measured by the consumer price index, the three-month bankers' acceptance rate, seasonally-adjusted retail sales in constant price terms, the 12-month outlook of manufacturers on skilled and unskilled employment as reflected by SACOB's manufacturing survey - three-month moving average, the gold price in dollar terms as fixed on the London Metal Exchange, merchandise imports in real terms, merchandise exports in real terms, the total number of new vehicles sold, the physical volume of manufacturing production - seasonally adjusted, the seasonally adjusted value of building plans passed in constant price terms, the number of insolvencies of individuals and partnerships - seasonally adjusted, and the price of shares traded on the Johannesburg Stock Exchange as indicated by the JSE overall index. Both the physical composition of the SACOB BCI and the primary function of this index of acting as a barometer of the economic environment justify its selection as a proxy for economic news events. It is interesting to note that SACOB became an agent of political change between 1990 and the national elections in 1994. Their publication, Business Voice, stated in 1997 that they had done this by becoming an "honest broker" between the business community and the major political players at the time, namely the National Party government and the ANC. For example, they visited the ANC in Lusaka before it was un-banned in order to convey their views on the economy, they made representations to the ANC to present a case for the lifting of sanctions before the elections, they sent numerous delegations to the National Party government and the ANC to persuade them to resume talks when negotiations foundered and they submitted various policy recommendations to all parties. As there is a lag of one month in the publication of the index, it is necessary to allow for a one-month lag when this variable is included in the data set. According to Pesaran and Timmerman (1995), this is standard practice in finance when dealing with such data.

Three risk factors fall into the categories of corporate affairs and markets as used by Reuters. These are the unexpected components of 
(1) Rate of change of the Dow-Jones industrial index

Bradfield (1990) investigated the influence of the NYSE on the behaviour of securities on the JSE. He found that 19 out of his sample of 30 randomly selected shares displayed statistically significant sensitivities to dollar returns on the Dow-Jones.

(2) Rate of change of the dollar/gold price of one ounce of pure gold

Barr (1990) suggested that economic activity in South Africa is to a large degree driven by the levels of gold/metal prices through their direct effect on the mining sector and their various trickle-through effects on the rest of the economy. Since the price of gold influences share returns, it was included as a risk factor.

(3) Rate of change of dividends in the financial and industrial sectors

Pesaran and Timmerman (1995) included the dividend yield as a candidate risk factor in their multifactor asset pricing model. It was decided not to use the dividend yield as a risk factor but rather to use dividends instead. The reason for this is that the dividend yield is correlated with the F \& I index.

A tenth factor, namely the residual market factor, was chosen for inclusion in all the linear factor models (LFMs). The residual market factor represents that variation in the market that is unexplained by the prespecified macroeconomic variables and is calculated using the methodology described in Reese (1993). It is essential to include this variable in this study if an ITNLSUR analysis is undertaken at a later stage (McElroy \& Burmeister [1988]).

In accordance with the arbitrage pricing theory, risk factors must be treated in order to calculate their unexpected movement. The unexpected movements in the factors were extracted by first calculating the rate of change of each risk factor, except for the term structure of interest rates where only the difference was taken, removing any autocorrelation up to seven lags and finally bringing the factor mean to zero. This methodology is consistent with that used by Van Rensburg (1995), Van Rensburg (1996), and Clare et al (1997).

The time series of all nine factors along with the financial and industrial index rate (the dependent variable in the linear factor model) were tested for stationarity using the Augmented Dickey-Fuller (ADF) 
test. This testing was done to avoid the Yule (1926) and Granger and Newbold (1974) spurious correlation problem that occurs when estimating the relationship between two nonstationary series. The probability values associated with the null hypothesis of the absence of a unit root in ADF were calculated. It was found that in all ten cases the probability values were significant at the $99 \%$ level of confidence.

\section{B. Share Selection}

A share selection technique similar to that utilized by Reese (1993) and Slaney (1995) was used in this study to select 57 shares. The following criteria were used to select the share sample:

(1) The shares must have been listed on the JSE for the entire duration of the study.

(2) The shares should be frequently traded so that the market price at a particular date could be assumed to be an accurate measure of the market's assessment of the worth of the share.

(3) The share sample should represent a high percentage of market capitalization of the JSE.

In calculating the rate of change on each of the shares chosen, because of the non-availability of data, dividends were excluded when calculating the return on shares, as done by Page (1986), Barr (1990), Reese (1993) and Van Rensburg (1996).

Enough work (Gilbertson \& Goldberg [1981]) has also been done on the JSE to confirm that it can be regarded as comprising two dichotomous sectors. This article has segmented the South African market and has concentrated on the industrial and financial sector to the exclusion of the gold mining and other related sectors. The dependent variable in the linear factor model is the financial and industrial index. To facilitate compatibility with the ITSUR methodology, the excess return realisation on the financial and industrial index was used. This was calculated by subtracting the risk-free rate from the financial and industrial rate. The three-month treasury bill tender rate was used as a proxy for the risk-free rate.

The share price data and the financial and economic data were obtained from the I-NET. This database is maintained and updated on a daily basis for share splits, consolidations and de-listings. 
TABLE 1. Percentage of Time That A Risk Factor is Priced in The LFM During the Three Sub-periods

\begin{tabular}{lcrrrrrrrr}
\hline & DJ & GOLD & TSD & INT & IFDIV & VOL & CRUDE & SACOB & CP18 \\
\hline Period 1 & 100 & 10 & 0 & 0 & 69 & 52 & 52 & 7 & 0 \\
Period 2 & 100 & 0 & 28 & 62 & 69 & 86 & 10 & 0 & 0 \\
Period 3 & 100 & 14 & 69 & 100 & 0 & 76 & 7 & 0 & 10 \\
Average & 100 & 8 & 32 & 54 & 46 & 71 & 23 & 2 & 3 \\
\hline
\end{tabular}

Note: The regressors are the unexpected rate of change of: DJ $=$ Dow-Jones index, $\mathrm{GOLD}=$ gold dollar price, $\mathrm{TSD}=$ term structure of interest rates, INT $=$ three-month bankers' acceptance rate, $\mathrm{IFDIV}=$ dividends, $\mathrm{VOL}=$ volume of shares traded, $\mathrm{CRUDE}=$ dollar spot price of Dubai crude oil, SACOBI = SACOB business confidence index lagged four weeks, CPI8= consumer price index lagged eight weeks. Period 1:20 October1991 to 9 January 1994; period 2: 10 January 1994 to 31 March 1996; period 3: 1 April 1996 to 21 June 1998.

\section{Selection of Instruments}

Following the suggestions of Amemiya (1977) and consistent with Priestley (1996), current and squared values of the exogenous variables (nine risk factors) were specified as instruments. For the market portfolio, the returns on the mining financial index were instrumented, as well as the squared values of the returns on this index and the fitted values and squared fitted values from a regression of the return on the market portfolio on the nine factors. The returns on the mining financial index were chosen as an instrument for the market portfolio. The mining financial index consists of mining companies that own a number of mines, most listed separately, that were originally established to raise capital to undertake exploration for minerals. Hence the index title of "mining financials". This index was chosen as its returns should not have any correlation with the error in the market (F \& I index) portfolio equation.

\section{Results}

\section{A. The Recursive Linear Factor Model}

Table 1 shows the percentage of time a risk factor is priced in the LFM during the three sub periods. The average number of regressors in each period is 6.8 and the average adjusted $\mathrm{R}^{2}$ for the entire period 


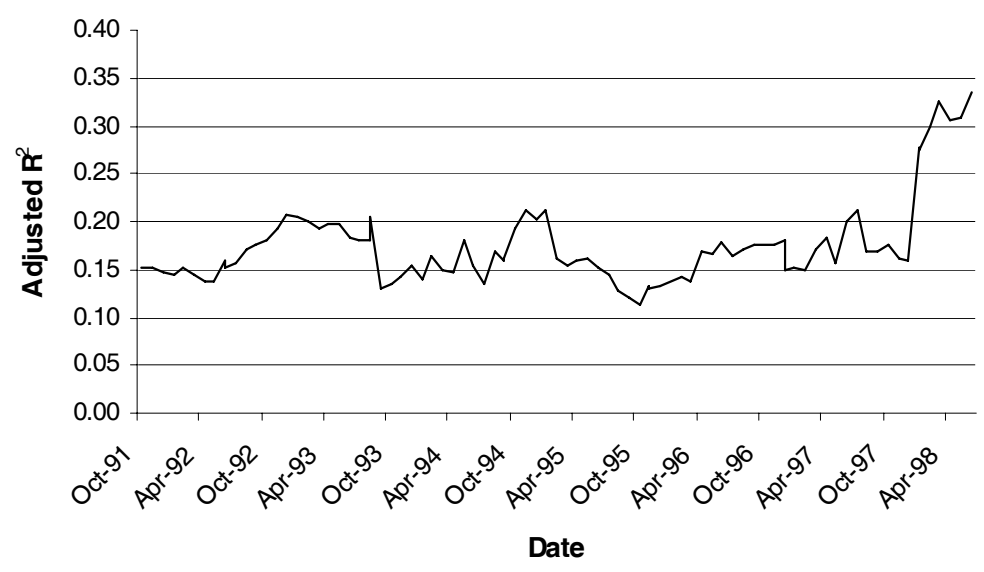

Figure 1. - Adjusted $\mathrm{R}^{2}$ of the Best Monthly Subset LFM Over Time Using Weekly Data

(16 October 1991 to 21 June 1998), is 21 percent. A plot of adjusted $\mathrm{R}^{2}$ vs time (figure 1) shows that it fluctuates around a limited range of a low value and then rises sharply at the beginning of 1997. This would suggest that in the event of a major regime switch in the economy such as the one introduced by the release of Nelson Mandela and the unbanning of the ANC, learning may take a long time to complete, as investors attempt to model, say, the new relationship between inflation, nominal interest rates and stock returns.

A table showing the $\mathrm{p}$ values of each Risk premium tested in the 87 APT models over the period 20 October 1991 to 21 June 1998 is available from the authors on request. ITNLSUR and N3SLS approaches were used with both the Gauss and the Marquardt minimization techniques. In summarizing the results (table 2) when the ITNLSUR technique failed to converge using the Gauss minimization technique the results of the Marquardt minimization method (15 of the 87 time periods) were used if the results over these instances could be confirmed by means of the N3SLS techniques.

\section{B. The ITNLSUR and N3SLS Techniques}

To determine whether the proportional appearance (frequency of occurrence) of a factor changed significantly from one period to 
TABLE 2. Percentage of Time That a Risk Factor is Priced in the APT Model During the Three Sub-periods

\begin{tabular}{llrrrrrrrr}
\hline & DJ & GOLD & TSD & INT & IFDIV & VOL & CRUDE & SACOB & CP18 \\
\hline Period 1 & 90 & 34 & 3 & 24 & 41 & 52 & 3 & 52 & 0 \\
Period 2 & 100 & 4 & 42 & 42 & 50 & 12 & 38 & 0 & 33 \\
Period 3 & 43 & 18 & 57 & 61 & 0 & 21 & 29 & 21 & 29 \\
Average & 78 & 19 & 34 & 42 & 30 & 28 & 23 & 24 & 21 \\
\hline
\end{tabular}

Note: The regressors are the unexpected rate of change of: DJ = Dow-Jones index, $\mathrm{GOLD}=$ gold dollar price, $\mathrm{TSD}=$ term structure of interest rates, INT $=$ three-month bankers' acceptance rate, $\mathrm{IFDIV}=$ dividends, $\mathrm{VOL}=$ volume of shares traded, $\mathrm{CRUDE}=$ dollar spot price of Dubai crude oil, SACOBI = SACOB business confidence index lagged four weeks, CPI8= consumer price index lagged eight weeks. Period 1:20 October1991 to 9 January 1994; period 2: 10 January 1994 to 31 March 1996; period 3: 1 April 1996 to 21 June 1998.

another, a z-test was performed on the data in the table above. In all instances the probability values associated with the null hypothesis of randomness were significant at the $99 \%$ level of confidence, except for three instances associated with the gold risk factor (period one to period two and period two to period three), the consumer price index risk factor (period one to period two and period two to period three) and the dividend risk factor (period one to period two). None of these three factors played an important role in the APT model.

An unexpected spin-off from this research was that the researchers were able to demonstrate that both the ITNLSUR and the 3NLS techniques are applicable on the JSE because they tended to produce similar results.

The results from the three sub-periods investigated are discussed below:

\section{October 1991 to 9 January 1994 (first sub-period)}

During this period the three most frequently priced risk factors in the APT model in order of importance were the Dow-Jones index, the volume of shares traded on the JSE and the SACOB business confidence index.

It comes as no surprise that the Dow-Jones index was the most frequently priced risk factor as Bradfield (1990) has documented the influence of this index on the JSE.

In this period leading up to the national elections, after an extended 
period of political maneuvering, it is not unexpected that the risk factor proxying for political events (the volume of shares traded on the JSE) would be the joint second most frequently priced risk factor.

It seems reasonable to expect that the prevailing uncertainty at that time would also have influenced the confidence of the business community (SACOB business confidence index) to such an extent that this factor would become an important risk factor priced in the APT model (joint second). The manner in which the SACOB BCI, which was designated as a proxy for economic events, became important during the turbulent period before the general elections would suggest that it has come to serve as a proxy for political events in the country. It appears that as SACOB became involved during the transitional phase before the national elections as an honest broker for political change, the business confidence index became politicized, with the result that the index began to reflect the confidence of business in the political future of this country and thus effectively became a proxy for political events. This was possibly achieved as a result of the way the business community responded to the manufacturing survey, which is one of the 13 indicators making up the SACOB BCI. Unfortunately SACOB gives no indication of the weight of each indicator in the total index. After the general elections when a democratically elected government had been installed and there was no need for SACOB to play a political role, the index reverted back to becoming an indicator of business confidence released monthly by SACOB for the benefit of its members, who use the index to ascertain the effect of the economic environment on their businesses.

Van Rensburg (1996) found that three factors were applicable to the JSE and were priced in the APT model during the period from January 1980 to December 1989. These were: returns on the Dow-Jones industrial index, the term structure of interest rates and inflation expectations2. Clearly the specification of the APT model has changed.

\section{January 1994 to 31 March 1996 (second sub-period)}

During this period the four most frequently priced risk factors in the APT model in order of importance were the Dow-Jones index, dividends paid by companies in the financial and industrial sectors, the three-month bankers' acceptance rate and the term structure of interest rates.

The apparent change in the specification of the APT model and the 
emergence of a new set of "priced" risk factors involving three of the four risk factors above are discussed in more detail under the third subperiod.

An unexpected finding was that the dividends paid by companies in the financial and industrial sectors were the second most frequently priced risk factor, especially in view of the fact that tax on dividends was abolished only in March 1990, in other words before it had had time to gain significance. However, on reflection, an explanation for this significance could be that before South Africa emerged from its isolation from the international community (April 1994), South African companies had very little opportunity for overseas expansion. During this period of isolation, successful South African companies, such as Anglo American, Sanlam, Rembrandt and Old Mutual, after buying as many local companies as they could, had no other option but to distribute their profits in the form of dividends. After the liberalization of foreign exchange controls, instead of paying high dividends to their stockholders, public companies started investing overseas. This would explain why dividends paid would be a significant risk factor (predictor variable) during South Africa's years of isolation, only to become totally insignificant once that isolation came to an end.

\section{April 1996 to 21 June 1998 (third sub-period)}

The risk factors that tended to be priced the most frequently during this period in order of importance were the three months bankers' acceptance rate, the term structure of interest rates and the Dow-Jones index.

Comparing sub-period two with sub-period three, it can be seen that with the exception of dividends the top risk factors priced during these sub-periods are the same. The fact that the second and third sub-periods (10 January 1994 to 31 March 1996 and 1 April 1996 to 21 June 1998) reveal that the same risk factors tend to be priced suggests that as the first sub-period coincided with the preparations for the 1994 national elections the second and third sub-periods, by virtue of their being similar, could be merged into a single post-election period extending from 10 January 1994 to 21 June 1998. Clearly, the specification of the APT model has changed since the national elections in April 1994. Since all the priced risk factors with the exception of the Dow-Jones index are proxies for economic events, it would appear that the economic environment now shapes the APT model. 
The most important economic event after the national elections was South Africa's joining the global economic community. Lamba and Otchere (2001) confirm that the JSE became more integrated, economically and financially, with other world markets around 1994, which was the time of the first democratically held elections.

Immediately after the elections South Africa experienced a sharp net inflow of foreign capital. Because of these inflows South Africa could afford to let the economy expand at a faster rate, foreign reserves increased sharply and foreign exchange controls were further relaxed. On the other hand, South Africa became more susceptible to the whims of foreign investors and the so called 'contagion effect' -that is events in other countries that are completely external to the affected economy but that affect perceptions of foreign investors (Stals [1998]).

\section{Conclusion}

Profound political changes in the early nineties and the Dow Jones Industrial index had the greatest effect on the value and volatility of South African assets immediately after the release of Nelson Mandela and the unbanning of the ANC. Key economic variables driving asset returns played a less prominent role in the early nineties.

The normalization of South Africa's external relations and the subsequent net inflow of capital after the elections in 1994 and the higher level of economic growth reversed the earlier dominance of political news events, with the result that economic events now dominate the APT model. This is a reversal of the situation that existed before the release of Nelson Mandela and the unbanning of the ANC.

More specifically, by examining the nature of the risk factors in the APT model, the researchers were able to conclude that political events had changed the specification of the APT model in late 1991. Since the national elections in April 1994, the acceptance of South Africa into the world community and the globalization of its economy have meant that there has been a further change in the specification of the APT model and that a different set of risk factors, primarily influenced by economic events, are currently priced in the APT model.

\section{References}

Akaike, H. 1973. Information Theory and an Extension of the Maximum Likelihood Principle. Second International Symposium on Information Theory, edited by B. N. Petrov \& F. Csaki. Budapest: Akademiai Kiado, 
267-281.

Amemiya, T. 1977. The maximum likelihood and the nonlinear three-stage least squares estimator in the general nonlinear simultaneous equation model. Econometrica 45(4): 955-968.

Barr, G. D. I. 1990. Macroeconomic identification of the pricing factors on the Johannesburg Stock Exchange. South African Journal of Business Management 22 (1): 17-26.

Berry, M.; Burmeister, E; and McElroy, MB. 1988. Sorting out risks using known APT factors. Financial Analysts Journal 44(2): 29-42.

Bradfield, DJ. 1990. A note on the seasonality of stock returns on the Johannesburg Stock Exchange. South African Journal of Business Management 21: 7-9.

Business Voice. November 1997. Sacob's role as “honest broker".

Chen, N.; Roll, R.; and Ross, SA. 1986. Economic forces and the stock market. Journal of Business 59:283-403.

Clare, A.; Priestley, R.; and Thomas, S. 1997. The robustness of the APT to alternative estimators. Journal of Business Finance \& Accounting (June): 645-655.

Chamberlain, G., and Rothschild, M. 1983. Arbitrage and mean variance analysis on large asset markets. Econometrica 51:1281-304.

Correia, C de J., and Wormald, MP. 1987. The association between stock market returns and rates of inflation. De Ratione 2(1): 11-18.

Gallant, RA. 1987. Nonlinear Statistical Models. New York: Wiley.

Garrett, I., and Priestley, R. 1997. Do assumptions about factor structure matter in empirical tests of the APT? Journal of Business Finance \& Accounting 24(2): 249-260.

Gilbertson, B., and Goldberg, M. 1981. The market model and the Johannesburg Stock Exchange. Investment Analysts Journal: 40-42.

Granger, CWJ., and Newbold, P. 1974. Spurious Regressions in Econometrics. Journal of Econometrics 2:111-120.

Henn, J., and Smit, EvdM. 1997. The influence of economic news events on share market activity. Investment Analysts Journal 46: 23-34.

Hermannssen, R. 1998. Focus on Asset Allocation: South African Investment Strategy HSBC Simpson Mckie (4).

Lamba, A. S., and Otchere I. 2001. An analysis of the dynamic relationships between the South African equity market and major world equity markets. Multinational Finance Journal 5: 201-224

Mboweni, T. T. 1999. Does the Yield curve contain useful information for the Reserve Bank? Address delivered at the Annual Convention of the Actuarial Society of South Africa, 2 November.

McElroy, MB., and Burmeister, E. 1988. Arbitrage pricing theory as a restricted nonlinear multivariate regression model. Iterated nonlinear seemingly unrelated regression estimates. Journal of Business \& Economic Statistics 6(1): 29-43. 
Nel, H. 1994. Monetary control and interest rates during the post-De Kock commission period. The South African Journal of Economics (March): 14-27.

Nel, H. 1996. The term structure of interest rates and economic activity in South Africa. The South African Journal of Economics (September): 161-174.

Page, MJ. 1986. Empirical testing of the APT using data from the Johannesburg Stock Exchange. South African Journal of Business Management 17:38-42.

Pesaran, M. H., and Timmermann, A. 1995. Predictability of stock returns: robustness and economic significance. Journal of Finance 4:1201-1228.

Priestley, R. 1996. The arbitrage pricing theory, macroeconomic and financial factors, and expectations generating processes. Journal of Banking \& Finance 20:869-890.

Reese, BK. 1993. The Arbitrage Pricing Theory in South Africa: an Empirical Study of the Effect of Pre-specified Risk Factors on Share Prices on the Johannesburg Stock Exchange. Master's dissertation. Durban: University of Natal.

Roberts, A. 1998. Enemy \#1: Inflation or interest rates? Financial Mail (July 31): 16 .

Ross, SA. 1976. The APT approach to strategic portfolio management. Financial Analysts Journal May-June 1984: 14-26.

Slaney, KBE. 1995. An Investigation into the Share Indices That Proxy the Macroeconomic Forces Underlying Equity Returns on the Johannesburg Stock Exchange. Master's dissertation. Durban: University of Natal.

Stals, CL. 1998. The Integration of the South African Financial System in the Global Markets. Address delivered at the National Forum of the National Bank of Belgium, 13 May.

Van der Merwe R., and Smit, E vd M. 1997. The influence of political news events on share market activity in South Africa. Investment Analysts Journal 44:11-23.

Van Rensburg, PJ. 1995. Macroeconomic variables and the Johannesburg Stock Exchange : a multi-factor approach. De Ratione 9(2): 45-63.

Van Rensburg, PJ. 1996. Macroeconomic identification of the priced APT factors on the Johannesburg Stock Exchange. South African Journal of Business Management 27:104-112.

Yule, GU. 1926. Why do we sometimes get nonsense correlations between time series? Journal of the Royal Statistical Society 89(1): 1-64. 